\title{
A genetic study of SSV1, the prototypical fusellovirus
}

\section{Eric Iverson and Kenneth Stedman*}

Biology Department, Center for Life in Extreme Environments, Portland State University, Portland, OR, USA

\section{Edited by:}

Frank T. Robb, University of Maryland, USA

\section{Reviewed by:}

Brian P. Hedlund, University of Nevada Las Vegas, USA

Matthias Hess, Washington State

University, USA

\section{${ }^{*}$ Correspondence:}

Kenneth Stedman, Biology

Department, Center for Life in

Extreme Environments, Portland

State University, P.O. Box 751,

Portland, OR 97207-0751, USA

e-mail:kstedman@pdx.edu
Viruses of thermophilic Archaea are unique in both their structures and genomic sequences. The most widespread and arguably best studied are the lemon-shaped fuselloviruses. The spindle-shaped virus morphology is unique to Archaea but widespread therein. The best studied fusellovirus is SSV1 from Beppu, Japan, which infects Sulfolobus solfataricus. Very little is known about the function of the genes in the SSV1 genome. Recently we have developed genetic tools to analyze these genes. In this study, we have deleted three SSV1 open reading frames (ORFs) ranging from completely conserved to poorly conserved: VP2, d244, and b129. Deletion of the universally conserved ORF b129, which encodes a predicted transcriptional regulator, results in loss of infectivity. Deletion of the poorly conserved predicted DNA-binding protein gene VP2 yields viable virus that is indistinguishable from wild-type. Deletion of the well-conserved ORF d244 that encodes a predicted nuclease yields viable virus. However, infection of $S$. solfataricus with virus lacking ORF d244 dramatically retards host growth, compared to the wild-type virus.

Keywords: DNA binding, nuclease, transcription factor

\section{INTRODUCTION}

Viruses of Archaea are very poorly understood with only about 50 known archaeal viruses relative to the ca. 5000 characterized viruses of bacteria, plants, and animals (Pina et al., 2011). The best studied of archaeal viruses are those infecting the thermoacidophiles, with an unprecedented new seven virus families introduced in the last few years to accommodate the astonishing morphological and sequence diversity present in these viruses (Pina et al., 2011).

The Sulfolobus spindle-shaped viruses (SSVs) of the family Fuselloviridae were the first discovered and probably the best studied family of archaeal viruses. SSVs are found throughout the world in high temperature $\left(>70^{\circ} \mathrm{C}\right)$ and acidic $(\mathrm{pH}<4)$ environments where their hosts, Sulfolobus solfataricus and its close relatives thrive (Wiedenheft et al., 2004; Held and Whitaker, 2009). The type virus, SSV1, encodes a positively supercoiled, $15.5 \mathrm{kbp}$ circular dsDNA genome (NC_001338.1) that is enclosed within a lemon or spindle-shaped capsid (Yeats et al., 1982; Martin et al., 1984; Nadal et al., 1986). The genome encodes 34 open reading frames (ORFs; Palm et al., 1991), most of which have no recognizable homologs apart from other Fuselloviridae. The only SSV1 gene with clear homology to proteins outside the Fuselloviridae is the viral integrase, encoded by ORF $\mathrm{d} 355$. The main structural proteins purified from virus particles are the major and minor capsid proteins VP1 and VP3 and the putative DNA packaging protein VP2 (Reiter etal., 1987a). More recently, mass spectrometric analysis of SSV1 virions revealed two additional proteins, the products of ORFs c792 and d244 (Menon et al., 2008; Figure 1).

In the absence of homologous sequences, three complementary approaches have been used to try and determine the function of the proteins encoded in the SSV1 genome; structural genomics, comparative genomics, and genetics. Atomic resolution structures have been obtained by C. Martin Lawrence and his group for proteins encoded by SSV1 ORFs b129, f112, d63, e96, f93, and d244 or their homologs from other fuselloviruses. The products of ORFs b129, f112, and $\mathrm{f} 93$ resemble transcriptional regulators and d244 a novel nuclease (Lawrence et al., 2009; Menon et al., 2010). However, the function of these proteins in virus replication remains to be determined. Two of these ORFs, b129 and d244, are the targets of the current study.

In parallel, we and others have undertaken comparative genomic studies. Fifteen ORFs are completely conserved in 12 canonical SSV genomes (Stedman et al., 2003; Wiedenheft et al., 2004; Held and Whitaker, 2009; Redder etal., 2009; Stedman, unpublished; Figure 1). Most of the universally conserved genes are clustered in half of the genome with the notable exception of the VP2 gene, a target of this study. Conservation in the rest of the genome is lower. Nonetheless, there are very few completely unique genes in the SSV1 genome (Figure 1). It is highly probable that the conserved genes are required for virus function, but again this has not been confirmed.

We developed methods for gene disruption in order to determine the requirements for genes in the virus genome directly. About 10 years ago, we showed that four SSV1 ORFs did not tolerate insertion of the $3.2 \mathrm{kbp}$ pBluescript plasmid and allow virus function. Twelve other SSV1 ORFs appeared, indirectly, to not tolerate insertion. However, two ORFs, e178 and e51, were able to tolerate insertion of the entire pBluescript plasmid (Stedman et al., 1999). This result allowed the development of viral shuttle vectors and the beginnings of Sulfolobus genetics (Jonuscheit et al., 2003). Insertion of the pBluescript plasmid and up to ca. $5 \mathrm{kbp}$ of exogenous DNA in these ORFs does not appear to have a noticeable effect on virus function (Stedman et al., 1999; Jonuscheit et al., 2003; Clore and Stedman, 2006; Albers et al., 2006).

However, insertion of large DNA fragments into the SSV1 genome is not straightforward and the possible insertion locations 


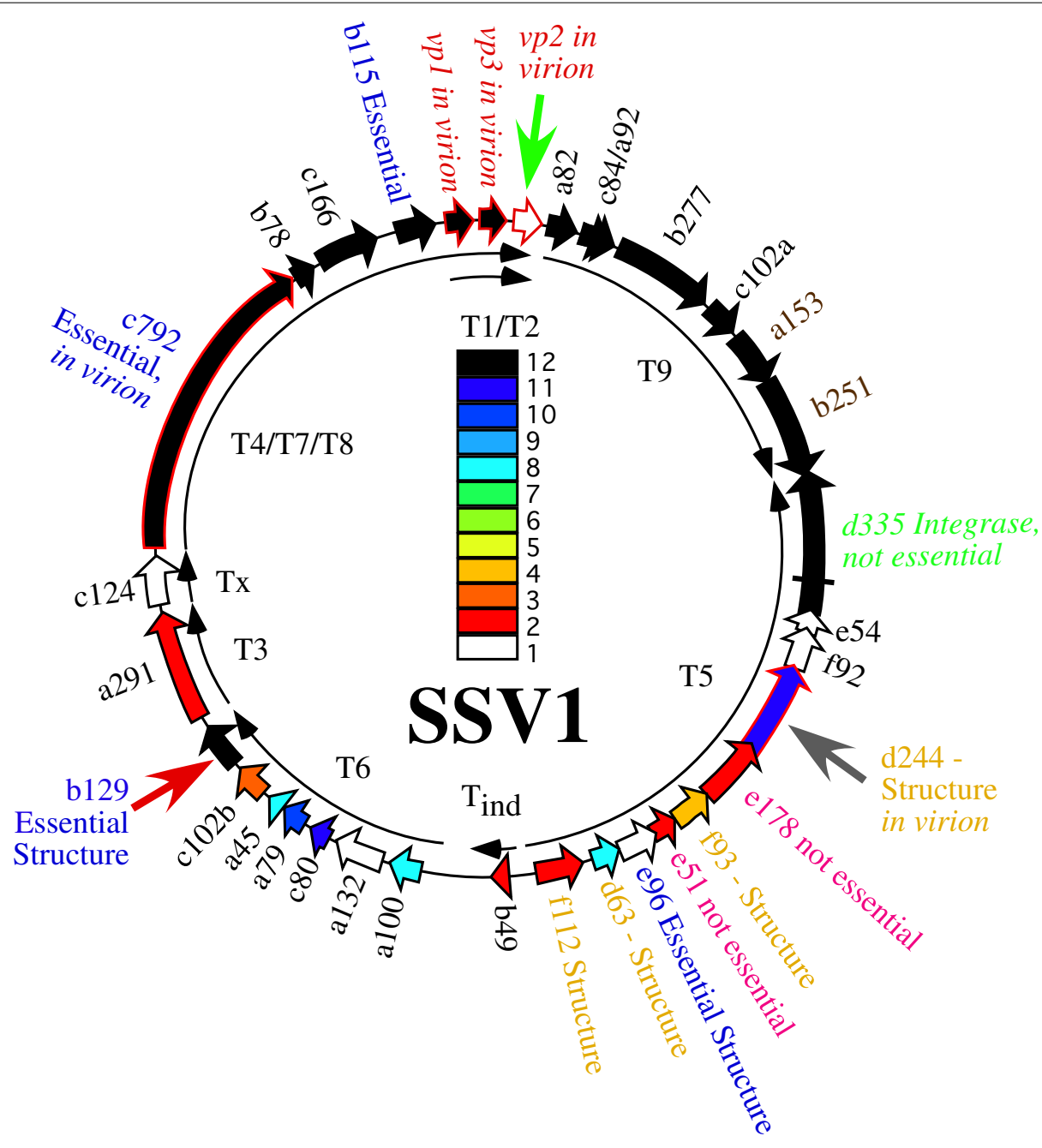

FIGURE 1 | Genome map of SSV1. Open reading frames are shown as block arrows and labeled as in Palm et al. (1991). Virus structural protein genes (Reiter et al., 1987a) and other proteins found in the virion (Menon et al., 2008) are outlined in red and labeled as "in virion." Conservation of open reading frames in 12 canonical SSV genomes (SSV1, SSV2, SSV3, SSV4, SSV5, SSVRH, SSVK1, SSVL, SSVKM1, SSVKU1, SSVL2, and SSVGV1; Redder et al., 2009; Held and Whitaker, 2009; Stedman, unpublished) is listed with the color code in the middle of the genome with ORFs conserved in 12 genomes in black, ORFs conserved in 11 genomes in dark blue, etc. ORFs which did not tolerate insertion of the pBluescript plasmid are labeled as "Essential" in blue type. ORFs allowing insertion of the pBluescript plasmid without loss of virus function are labeled as "not essential" (Stedman etal., 1999). All ORFs whose products have been crystallized and structure determined are labeled as "Structure" (Lawrence et al., 2009; Menon et al., 2010). The gene for the SSV1-integrase is labeled in green and was shown to be not essential by deletion (Clore and Stedman, 2006). Transcripts are labeled as curved thin arrows (Reiter et al., 1987b; Fröls et al., 2007). ORFs targeted in this study are indicated with large arrows outside the genome map. are limited. Therefore, Long Inverse PCR (LIPCR) using highfidelity highly processive DNA polymerases (e.g., Phusion ${ }^{\circledR}$ ) was developed to specifically change the SSV1 genome at single nucleotide resolution. LIPCR was used to delete precisely the SSV1 viral integrase gene. Surprisingly, this "integrase-less" SSV1 was functional (Clore and Stedman, 2006). However, consistent with its conservation, the virus lacking the integrase gene is at a competitive disadvantage relative to integrase-containing viruses (Clore and Stedman, 2006). All of the SSV1 ORFs that can be deleted or tolerate insertion without abrogating virus function are in the "early" transcript, T5, that is induced soon after UV-irradiation of SSV-infected cultures (Reiter et al., 1987b; Fröls et al., 2007).
Three ORFs in the SSV1 genome were targeted for gene disruption in this study. The VP2 gene (NP_039802.1) was chosen for disruption because it is only present in SSV1 and the very distantly related SSV6 (Held and Whitaker, 2009; Redder et al., 2009), and is in the middle of the most highly conserved part of fusellovirus genomes (Figure 1). VP2 has DNA-binding activity (Reiter et al., 1987a; Iverson and Stedman, unpublished) that is presumably required for DNA packaging. ORF b129 (NP_039795.1) was chosen because it is intolerant of insertional mutagenesis (Stedman et al., 1999), a high resolution structure is known (Lawrence et al., 2009) and the gene is completely conserved in all SSVs (Figure 1). Finally, ORF d244 (NP_039781.1) was chosen for gene disruption because a high-resolution structure of its homolog from SSVRH 
is known (Menon et al., 2008) and it is conserved in most SSV genomes with the exception of SSVK1.

\section{MATERIALS AND METHODS CULTURE CONDITIONS}

Sulfolobus solfataricus strains, Table 1, were grown aerobically at $76^{\circ} \mathrm{C}$ on plates or in liquid media containing yeast extract and sucrose as carbon and energy sources (YS Media), both as in Jonuscheit et al. (2003). Escherichia coli strains were grown in LB medium at $37^{\circ} \mathrm{C}$ as suggested by the manufacturer (Novagen).

\section{PURIFICATION OF DNA}

Plasmid DNA used for LIPCR was purified from E. coli using the alkaline lysis method of Birnboim and Doly (1979). Plasmid DNA used to transform Sulfolobus was purified using the GeneJet Plasmid Purification Kit (Fermentas) following the manufacturer's protocols. Total genomic DNA was isolated from S. solfataricus in late log phase growth (OD600 0.6) as in Stedman et al. (1999). Plasmid DNA was purified from a $50 \mathrm{~mL}$ culture of S. solfataricus transformed with SSV- $\Delta \mathrm{d} 244$ (late log, OD600 0.6) using the GeneJet plasmid purification kit (Fermentas) following the manufacturer's protocols. This DNA was retransformed into E. coli (Novagen), purified therefrom and analyzed by restriction endonuclease digestion with EcoRI (Fermentas).

\section{CONSTRUCTION OF SSV1 DELETION MUTANTS}

Deletion mutants were constructed from the pAJC97 shuttle vector using LIPCR (Clore and Stedman, 2006). Primers were designed to overlap with the start and stop codon of the ORF to be deleted to keep the deletion in frame. Initially primers were designed using the archaea genome browser ${ }^{1}$. Primer melting temperatures were matched and then checked for potential primer dimer and secondary structure formation using online tools from IDT ${ }^{2}$. Table 2 contains a list of oligonucleotide sequences used. LIPCR was performed using Phusion ${ }^{\circledR}$ High-Fidelity DNA Polymerase (NEB/Finnzymes) at a final concentration of $0.005 \mathrm{U} / \mu \mathrm{L}$. LIPCR cycling conditions as follows: initial denaturation at $98^{\circ} \mathrm{C}$ for $3 \mathrm{~min} ; 35$ cycles of $98^{\circ} \mathrm{C}$ for $15 \mathrm{~s}$, annealing for $15 \mathrm{~s}, 72^{\circ} \mathrm{C}$ for $6 \mathrm{~min}$, and a final extension at $72^{\circ} \mathrm{C}$ for $6 \mathrm{~min}$. The annealing temperatures for deletion of VP2, ORF d244, and ORF b129 were 59,53 , and $66^{\circ} \mathrm{C}$, respectively. DNA was precipitated directly from LIPCR reactions using sodium acetate at a final concentration of $0.3 \mathrm{M}$ and 95\% EtOH. This DNA was phosphorylated using T4 polynucleotide kinase according to the manufacturer's protocols (Fermentas). DNA was ligated overnight $(\sim 20 \mathrm{~h})$ at $16^{\circ} \mathrm{C}$ using 5 Weiss units of T4 DNA ligase (Fermentas). Ligated DNA was transformed into NovaBlue Singles chemically competent E. coli following the manufacturer's protocol (Novagen). Plasmids were purified from single colonies and deletion constructs were identified by restriction endonuclease digestions. The deletion borders were confirmed by sequencing of the plasmids.

\section{ELECTROPORATION OF SULFOLOBUS}

Purified plasmid DNA was electroportated into Sulfolobus strain

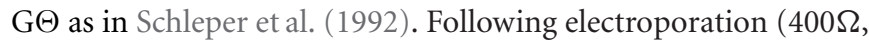

${ }^{1}$ http://archaea.ucsc.edu

${ }^{2}$ http://www.idtdna.com
$1.5 \mathrm{kV}, 25 \mu \mathrm{F})$, cells were immediately resuspended in $1 \mathrm{~mL}$ of YS media at $75^{\circ} \mathrm{C}$ and incubated for $1 \mathrm{~h}$ at $75^{\circ} \mathrm{C}$. The cells were then added to $50 \mathrm{~mL}$ of prewarmed $\mathrm{YS}$ media $\left(75^{\circ} \mathrm{C}\right)$ and grown in liquid media as outlined below.

\section{SCREEN FOR FUNCTIONAL INFECTIOUS VIRUS/HALO ASSAY}

To confirm the presence of infectious virus, halo assays were performed in duplicate 48 and $72 \mathrm{~h}$ post-electroporation (Stedman et al., 2003). Uninfected Sulfolobus $\mathrm{G} \Theta$ cells were diluted to an OD600 $\mathrm{nm}=\sim 0.3$ and allowed to grow until the OD600 nm reached $\sim 0.35$ (about $2.5 \mathrm{~h}$ ). Half of a milliliter of this uninfected culture was added to $5 \mathrm{~mL}$ YS media containing $0.2 \% \mathrm{wt} / \mathrm{vol}$ Gelrite ${ }^{\circledR}$ as a softlayer and poured onto prewarmed YS plates. Two microliters of supernatant from electroporated cultures was spotted onto the lawns and plates were incubated at $75^{\circ} \mathrm{C}$ for up to 3 days. A halo of host growth inhibition, typically observed 48 $72 \mathrm{~h}$ after incubation, indicated the presence of an infectious virus (Figure 2).

\section{GROWTH CURVES}

Portions of halos of growth inhibition from infected S. solfataricus $\mathrm{G} \Theta$ cells were removed from plates with a sterile pipette tip and inoculated into liquid YS media. The culture was grown to an OD600 nm of $\sim 0.6$. One milliliter of this culture was diluted in $100 \mathrm{~mL}$ YS media to an OD600 0.050. Cultures were placed in a shaking incubator at $75^{\circ} \mathrm{C}$ and the $\mathrm{OD} 600 \mathrm{~nm}$ was measured

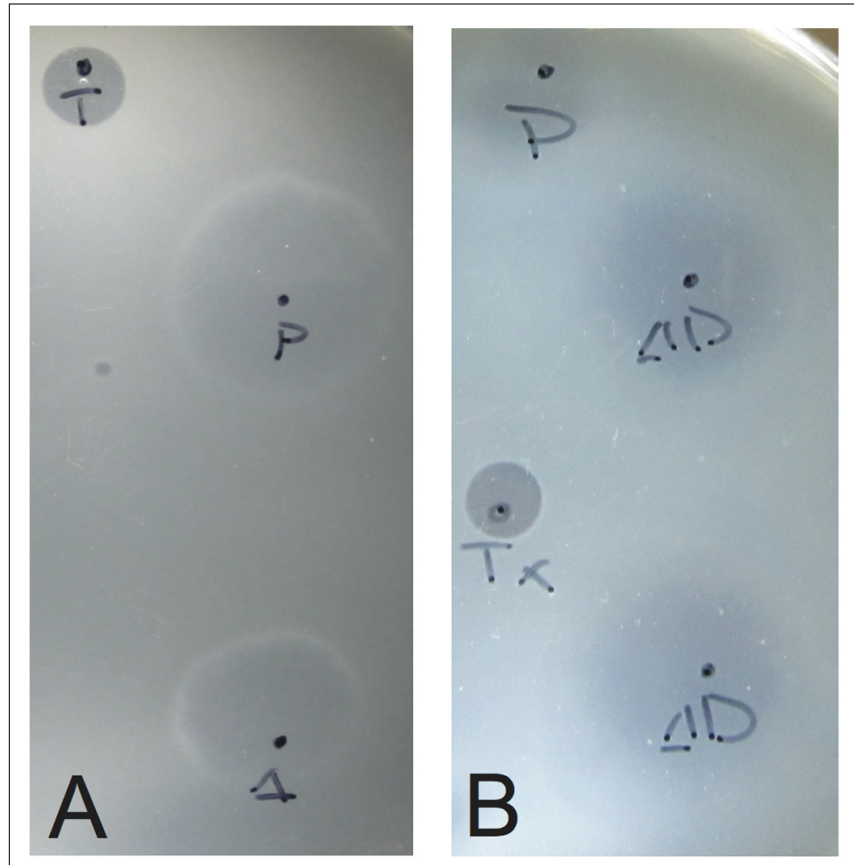

FIGURE 2 | Typical growth inhibition of $\boldsymbol{S}$. solfataricus on plates due to infectious virus. Lawns of $S$. solfataricus strain $\mathrm{G} \Theta$ were prepared as in Stedman etal. (2003). Two microliters of supernatant from cultures transformed with either (A) SSV- $\Delta$ VP2 or (B) SSV- $\Delta$ d244 were placed on the lawns where indicated. $\Delta$ indicates where SSV- $\Delta$ VP2 was spotted, $\Delta D$ where SSV- $\Delta d 244$ was spotted. $P$ indicates SSV-WT spotted as a positive control. T or Tx indicates $2 \mu \mathrm{L}$ of $0.01 \%$ Triton $\mathrm{X}-100$ spotted as a control for lawn growth. 
every $24 \mathrm{~h}$. After $96 \mathrm{~h}, 1 \mathrm{~mL}$ of culture was diluted into $100 \mathrm{~mL}$ fresh YS media and returned to $75^{\circ} \mathrm{C}$. One milliliter of culture was removed $72 \mathrm{~h}$ after each dilution, cells removed by centrifugation (14000 rpm for $5 \mathrm{~min}$ in a microcentrifuge) and the supernatant was screened for virus using the halo assay above.

\section{TRANSMISSION ELECTRON MICROSCOPY}

Supernatant from infected cultures was collected by centrifugation at $14,000 \mathrm{rpm}$ for $5 \mathrm{~min}$ in a microcentrifuge. Five microliters of supernatant was absorbed onto a 400 mesh carbon/formvar grid (Ted Pella) for $2 \mathrm{~min}$ and negatively stained with $2 \%$ uranyl acetate for $20 \mathrm{sec}$. Grids were viewed on a JEOL 100CX TEM operated at $100 \mathrm{keV}$ and images captured with a Gatan imager.

\section{RESULTS}

\section{SSV1 IS INFECTIOUS WITHOUT THE VP2 GENE}

The VP2 protein was purified from SSV1 virus particles and reported to be a DNA-binding protein (Reiter et al., 1987a). Surprisingly, a gene for VP2 was not found in SSV2 (Stedman et al., 2003) or SSVRH or SSVK1 (Wiedenheft et al., 2004). Moreover, a homolog is not present in the S. solfataricus or $S$. islandicus genomes (She et al., 2001; Reno et al., 2009; Guo et al., 2011). However, a very distant relative of SSV1, SSV6, which also contains an atypical putative tail fiber protein, has a VP2 gene (Redder et al., 2009). Thus, it is not clear whether SSV1 can function without a VP2 gene.

Therefore, we made an in-frame deletion of the majority of the VP2 gene by LIPCR in the context of the pAJC97 SSV1 shuttle vector (Clore and Stedman, 2006), leaving the first four codons and the last four codons (including the stop codon) of the ORF intact (see Table 1). The putative promoter for the T9 "early" transcript was also left intact. The construct containing the deletion, pAJC97$\triangle \mathrm{VP} 2$, is hereafter referred to as SSV- $\triangle \mathrm{VP} 2$.

To determine if the SSV- $\triangle \mathrm{VP} 2$ was able to make infectious virus, the shuttle vector was electroporated into $S$. solfataricus strain $\mathrm{G} \Theta$. Two days after electroporation, the supernatant from the transformed strains caused inhibition of growth of uninfected S. solfataricus strain G $\Theta$ on plates (Figure 2) that was indistinguishable from growth inhibition caused by the virus containing the VP2 gene. Similar growth inhibition was also observed on lawns of uninfected S. solfataricus strain S443, a new S. solfataricus isolate from Lassen Volcanic National Park that is a host

Table 1 | Strains and plasmid vectors used in this work.

\begin{tabular}{lll}
\hline Strain/vector & Description & Reference \\
\hline S. solfataricus G & MT4 Derivative & Cannio et al. (1998) \\
S. solfataricus S443 & Novel Sulfolobus isolate & Unpublished data \\
E. coli NovaBlue ${ }^{\circledR}$ & Expression strain & Novagen, Inc. \\
pAJC97 & SSV1 with TOPO PCR Blunt II & Clore and Stedman \\
& & (2006) \\
pAJC97- VPP2 & pAJC97 lacking VP2 gene & This Work \\
pAJC97- $\Delta$ d244 & pAJC97 lacking ORF d244 & This Work \\
pAJC97- $\Delta$ b129 & pAJC97 lacking ORF b129 & This Work
\end{tabular}

for all tested SSVs (Ceballos et al., in preparation). Moreover, the supernatant contained SSV-like particles when observed by transmission electron microscopy (Figure 3).

Infection by wild-type SSV1 and shuttle vectors does not drastically slow growth of cells in liquid culture for unknown reasons (Martin et al., 1984; Schleper et al., 1992; Stedman et al., 1999). The same is true of SSV- $\triangle$ VP2 (Figure 4). Infection with SSV- $\Delta$ VP2 was confirmed via PCR amplification (data not shown)

\section{SSV1 CONSTRUCTS LACKING THE CONSERVED ORF b129 DO NOT APPEAR TO MAKE INFECTIVE VIRUSES}

The b129 ORF in SSV1 is universally conserved in all fuselloviruses (Redder et al., 2009). Moreover shuttle vectors with pBluescript inserted into ORF b129 did not produce infective virus when electroporated into Sulfolobus (Stedman et al., 1999). However, a similar insertion mutant in the equally conserved SSV1 viral integrase appears to be non-functional (Stedman et al., 1999), but an in-frame deletion was functional (Clore and Stedman, 2006). A structure for the b129 ORF is also known (Lawrence et al., 2009) and it contains two Zn-finger putative DNA-binding motifs.

The b129 ORF was deleted with LIPCR. The deletion of the b129 ORF left the first four and last two codons of the ORF intact and maintained the predicted T3 promoter (Reiter et al., 1987b). This construct is referred to as SSV- $\Delta$ b129. Unlike the SSV- $\Delta$ VP2 construct, supernatants from Sulfolobus cells electroporated with SSV1- $\Delta$ b129 did not cause zones of growth inhibition when spotted on lawns of uninfected $S$. solfataricus strain $\mathrm{G} \Theta$. A total of nine independent transformations were performed in which the wild-type virus consistently caused growth inhibition but SSV$\Delta$ b129 did not. Moreover, no halos of growth inhibition were formed on lawns of $S$. solfataricus strain S443. It is not currently known at which step of virus replication the SSV- $\Delta$ b129 is deficient.

\section{SSV1 LACKING ORF d244 IS INFECTIOUS BUT HAS A NOVEL PHENOTYPE}

SSV1 ORF d244 is in the UV-inducible transcript T5, upstream of the viral integrase gene (Figure 1). The entire pBluescript plasmid can be inserted into the ORF directly upstream of ORF d244 without abrogating SSV1 function (Stedman et al., 1999). ORF d244 is well conserved in other Fusellovirus genomes with the exception of SSVK1 (Wiedenheft et al., 2004; Redder et al., 2009). The X-ray crystal structure of the homolog of SSV1 ORF d244, SSVRH ORF d212 has been solved and it is predicted to be a nuclease (Menon et al., 2010). Moreover, the product of ORF d244 has been reported to be in purified SSV1 particles (Menon et al., 2008).

The SSV1 d244 ORF was deleted with LIPCR. The deletion of the $\mathrm{d} 244$ ORF left the first two and last three codons of the ORF intact as well as maintained the ORF to avoid polar effects. This construct is referred to as SSV- $\Delta \mathrm{d} 244$.

To determine if SSV- $\Delta \mathrm{d} 244$ was able to make infectious virus, the shuttle vector was electroporated into $S$. solfataricus strain $\mathrm{G} \Theta$. Two days after electroporation, the supernatant from the transformed strains caused inhibition of growth of uninfected S. solfataricus strain $\mathrm{G} \Theta$ on plates (Figure 2) and also inhibited growth of $S$. solfataricus strain S443 (data not shown). 
Table 2 | Oligonucleotides used in this work.

\begin{tabular}{lll}
\hline Name & Sequence & Description \\
\hline VP2 LIPCR F & $5^{\prime}$-CAC CGC AAG TAG GCC-3' & Flanks VP2 gene for deletion \\
VP2 LIPCR R & $5^{\prime}$-CAC CCA CTT CAT ATC ACT CC-3' & Flanks VP2 gene for deletion \\
d244 LIPCR F & $5^{\prime}$-ATC CATTTA CCA TAA TCC ACC-3' & Flanks ORF d244 for deletion \\
d244 LIPCR R & $5^{\prime}$-GGA AAA TGA TAT TCA ACT CAG AGG-3' & Flanks ORF d244 for deletion \\
b129 LIPCR F & $5^{\prime}$-AGT TAG GCT CTT TTT AAA GTC TAC C-3' & Flanks ORF b129 for deletion \\
b129 LIPCR R & $5^{\prime}$-TGA CTC CGT CAT CCT CTA AC-3' & Flanks ORF b129 for deletion \\
VP2 Check F & $5^{\prime}$-ATT CAG ATT CTG WAT WCA GAA C-3' & Amplifies VP2 gene and flanking sequences \\
VP2 Check R & $5^{\prime}$-TCS CCT AAC GCA CTC ATC-3' & Amplifies VP2 gene and flanking sequences \\
d244 Check F & $5^{\prime}$-GGA ACT CCT CTC ATT AAC C-3' & Amplifies ORF d244 and flanking sequences \\
d244 Check R & $5^{\prime}$-GAT CAT CAA CGA GTA TAT TGA CC-3' & Amplifies ORF d244 and flanking sequences \\
b129 Check F & $5^{\prime}$-ATG AAG GCT GAG GAA ACA ATC GTG-3' & Amplifies ORF b129 and flanking sequences \\
b129 Check R & $5^{\prime}$-TTA ATA TAG CTG CGA TGC AGT ATA GTT TAT TTG TGC-3' & Amplifies ORF b129 and flanking sequences
\end{tabular}

*Underlined sequence indicates ORF.

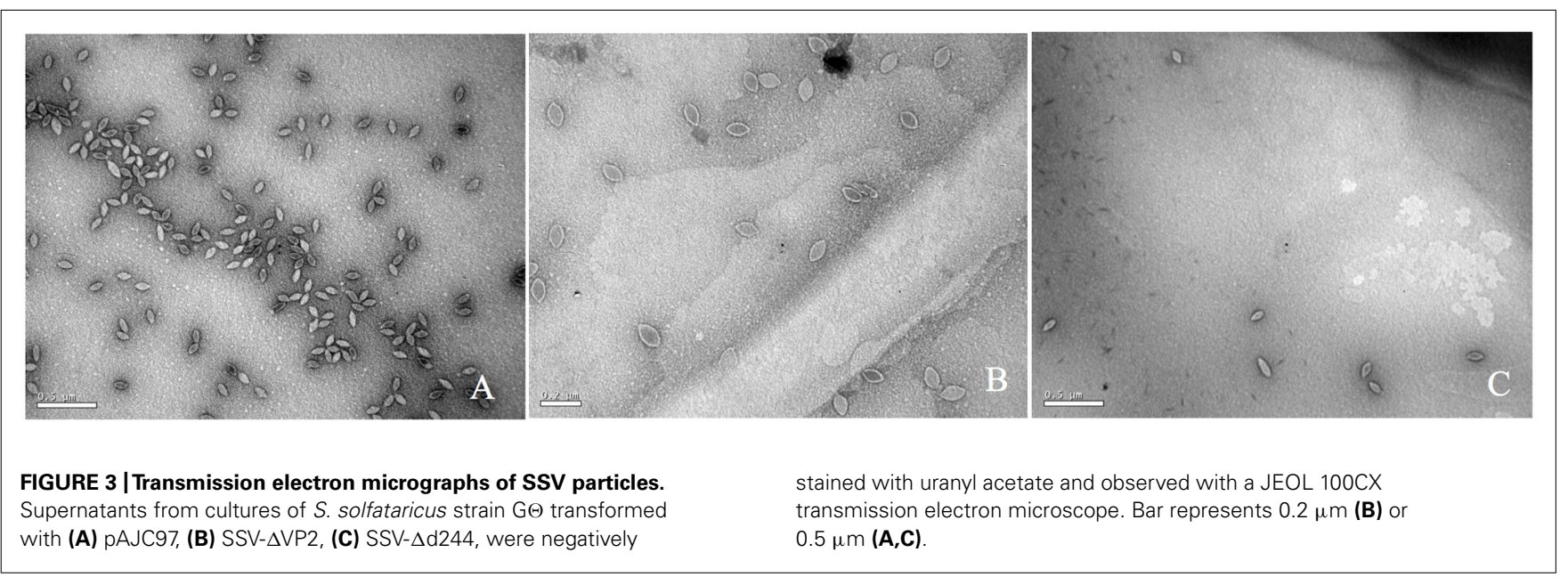

The supernatant contained SSV-like particles when observed by transmission electron microscopy (Figure 3).

Infection by wild-type SSV1, shuttle vectors and SSV- $\triangle \mathrm{VP} 2$ does not slow growth of cells in liquid culture (Martin et al., 1984; Schleper etal., 1992; Stedman etal., 1999; see above). However, infection by SSV- $\Delta \mathrm{d} 244$ drastically slows growth of S. solfataricus strains $\mathrm{G} \Theta$ and $\mathrm{S} 443$ in liquid culture (Figure 4). Infection with SSV- $\Delta \mathrm{d} 244$ was confirmed via PCR. Moreover, restriction endonuclease digestion of viral DNA recovered from transformed $S$. solfataricus cells and retransformed into $E$. coli revealed no obvious alterations of the SSV- $\Delta \mathrm{d} 244$ construct (data not shown).

\section{DISCUSSION \\ THE PUTATIVE DNA PACKAGING PROTEIN VP2 IS NOT REQUIRED FOR SSV1 FUNCTION}

The deletion of VP2 from SSV1 results in a functional virus that is indistinguishable from the wild-type virus (Figures 2-4). Based on the lack of conservation of VP2 this result is not completely unexpected. However, almost all viruses contain a genome packaging protein. There is no clear sequence homolog of VP2 in the host genome, but there are a number of small DNA-binding proteins, such as Sso7d or Cren7 that may be able to functionally substitute for VP2 in SSV1 genome packaging (Choli et al., 1988; Guo et al., 2008). This will be tested with mass spectrometry of SSV$\triangle \mathrm{VP} 2$ particles. Alternatively, the VP2 protein may be involved in maintenance of the positive supercoiling of the SSV1 viral genome (Nadal et al., 1986). It would be interesting to know if the topology of the viral DNA is affected by the absence of VP2. It is predicted that positive supercoiling should increase the thermal stability of the DNA, so SSV- $\triangle \mathrm{VP} 2$ may be less thermally stable than the wild-type virus.

The VP2 gene may be more prevalent than previously thought. VP2-like sequences have been reported from metagenomic studies, one in an acid mine drainage metagenome (Andersson and Banfield, 2008) and the other from Boiling Springs Lake in California (Diemer and Stedman, unpublished). These VP2 genes may be in the context of a SSV6 or ASV-like genome (Redder et al., 2009). 


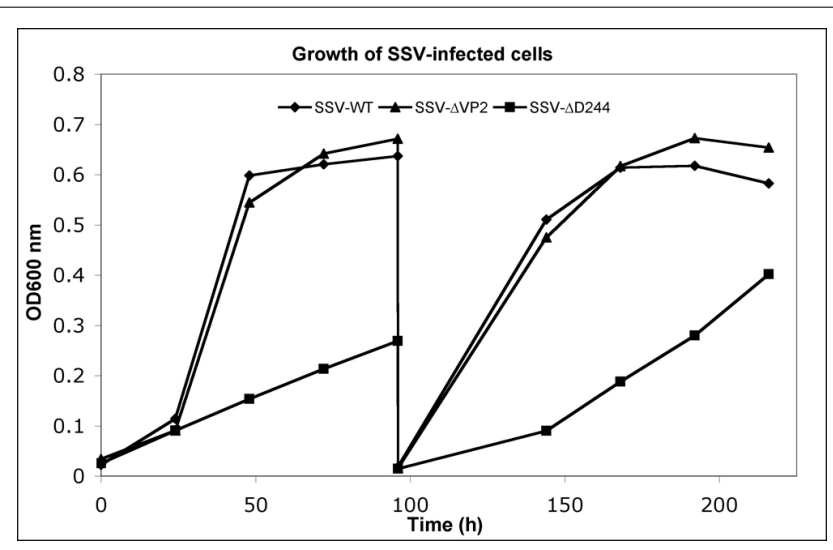

FIGURE 4 | Typical growth inhibition in liquid culture of virus constructs. Cultures of $S$. solfataricus $\mathrm{G} \Theta$ infected with wild-type SSV1, diamonds, SSV- $\triangle \mathrm{VP} 2$, triangles and SSV- $\Delta \mathrm{d} 244$, squares, were diluted in YS media to equal starting OD600 $\mathrm{nm}$ and incubated at $75^{\circ} \mathrm{C}$. At the indicated times, samples were removed and the OD600 $\mathrm{nm}$ was determined and the presence of virus was confirmed in each culture via halo assay. After $96 \mathrm{~h}$, $1 \mathrm{~mL}$ of cells were diluted 1:100 in fresh YS media and returned to $75^{\circ} \mathrm{C}$.

\section{THE PRODUCT OF ORF b129 APPEARS TO BE ESSENTIAL FOR SSV1 INFECTIVITY}

Homologs of SSV1 ORF b129 are present in all known SSVs (Redder et al., 2009). The b129 ORF also does not tolerate insertion of the pBluescript plasmid (Stedman et al., 1999). Thus, it is not surprising that deletion of ORF b129 leads to an incompletely replicating virus. However, the SSV1 integrase, a gene also conserved in all fuselloviruses, did not appear to tolerate insertion of pBluescript (Stedman et al., 1999), but could be deleted with LIPCR without abrogating virus function (Clore and Stedman, 2006). This indicates that either polar effects are important, which seems unlikely since the SSV1 integrase is at the end of the T5 transcript, or that insufficient replicate transformations were performed in the earlier study.

Nine replicate transformations of S. solfataricus with SSV$\Delta$ b129 did not generate functional virus. However, we cannot absolutely determine that SSV1 ORF b129 is essential for virus function without complementation experiments, which are underway. The reasons for the apparent necessity of SSV1 ORF b129 are unclear, but the structure of the b129 ORF product, a predicted transcriptional regulator (Lawrence et al., 2009) and induction of the T6 transcript containing ORF b129 after UVirradiation (Reiter et al., 1987b; Fröls et al., 2007) provides clues to its function.

The assay used herein for virus infection, ability to cause a zone of growth inhibition on a lawn of uninfected cells, is for virus spread and infectivity. There are many other aspects of virus replication that could be affected by disruption of ORF b129. An attractive hypothesis is that the b129 protein activates transcription of virus structural genes encoded by the "late" transcripts T7/8/9, T1, and T2 (Reiter et al., 1987b; Fröls et al., 2007; see Figure 1). This would be one of very few archaeal transcriptional activators characterized to date and the only the second archaeal viral transcriptional activator (Kessler et al., 2006). Thus, the SSV- $\Delta$ b129 construct may be able to replicate its genome, integrate into the host, and have genome replication induced by UV-irradiation or some subset of these activities. Experiments to test these hypotheses are underway.

\section{TRANSFECTION WITH SSV- $\Delta$ d244 PRODUCES VIRUS AND RETARDS HOST CELL GROWTH}

The SSV1 d244 ORF is well-conserved in fuselloviruses with the exception of SSVK1 (Wiedenheft et al., 2004; Redder et al., 2009). However, SSV1 lacking ORF d244 clearly makes infectious virus particles (Figures 2 and 3 ). Moreover, the zones of clearing produced by supernatants of cells transfected with SSV- $\Delta \mathrm{d} 244$ are clearer than those produced by either the wild-type or SSV- $\Delta$ VP2 viruses (Figure 3; unpublished data). They are reminiscent of zones of clearing produced by SSVK1 (data not shown). Unlike wild-type virus and SSV- $\Delta$ VP2, transfection by SSV- $\Delta \mathrm{d} 244$ leads to drastically reduced host growth (Figure 4). The reasons for this growth inhibition are unclear. Similar growth phenotypes have been observed in SSVK1 infections (Stedman et al., in preparation). SSVK1 consistently produces more virus than similar cultures of the wild-type virus, so this may account for the growth defect (unpublished data). Whether SSV- $\Delta \mathrm{d} 244$ consistently produces more virus than the wild-type or SSV- $\triangle \mathrm{VP} 2$ is currently unknown.

The structure of the product of SSV1 ORF d244 is a predicted nuclease (Menon et al., 2010), similar to Holiday junction resolvase enzymes. Why the lack of a resolvase leads to slower host growth is unclear. Possibly SSV1 ORF d244 is involved in the specificity of SSV1 integration. SSV-K1 is known to integrate into multiple positions in the host genome (Wiedenheft et al., 2004), which may contribute to its higher copy number. Whether SSV- $\Delta \mathrm{d} 244$ integrates into multiple positions in the host genome is under investigation. On the other hand, there may be a defect in SSV$\Delta \mathrm{d} 244$ replication or resolution of SSV replication intermediates that leads to accumulation of aberrant DNA, which, in turn, leads to slower host growth.

After multiple transfers of Sulfolobus cultures transfected with SSV- $\Delta \mathrm{d} 244$ into fresh media, growth rates recover to near wildtype rates (unpublished data). The virus is still present in these cultures by PCR and is able to inhibit Sulfolobus growth on plates (unpublished data) so the virus is not lost or apparently rearranged (see Results). Whether there are other genetic changes in the virus or host under these conditions remains to be determined. One attractive possibility is changes to the CRISPR repeat structures that are proposed to be important for acquired immunity in Sulfolobus (Held and Whitaker, 2009).

\section{SUMMARY AND OUTLOOK}

Comparative and structural genomics has identified a number of targets for gene disruption in the SSV1 genome. Here precise gene disruptions of the poorly conserved VP2 gene, and the well-conserved ORFs b129 and d244 are described. Deletions in VP2 may allow insights into DNA packaging in the SSV1 genome. Deletion of ORF b129 may allow the identification of the second archaeal virus transcriptional activator. Deletion of ORF d244 may allow insight into copy number regulation in SSVs, previously thought to be regulated by ORF d63 (Lawrence et al., 2009). Clearly, there are many more genes to be analyzed in the SSV1 
genome and more insights that can be gained by combining comparative genomics, structural biology, and genetics. In the future, biochemical work will be added to this suite of techniques to gain fundamental understanding of this fascinating, unique, and ubiquitous archaeal virus family.

\section{REFERENCES}

Albers, S. V., Jonuscheit, M., Dinkelaker, S., Urich, T., Kletzin, A., Tampé, R., Driessen, A. J., and Schleper, C. (2006). Production of recombinant and tagged proteins in the hyperthermophilic archaeon Sulfolobus solfataricus. Appl. Environ. Microbiol. 72, 102-111.

Anderson, A. F., and Banfield, J. F. (2008). Virus population dynamics and acquired virus resistance in natural microbial communities. Science 320, 1047-1050.

Birnboim, H. C., and Doly, J. (1979). A rapid alkaline extraction procedure for screening recombinant plasmid DNA. Nucleic Acids Res. 7, 15131523.

Cannio, R., Contursi, P., Rossi, M., and Bartolucci, S. (1998). An autonomously replicating transforming vector for Sulfolobus solfataricus. J. Bacteriol. 180, 3237-3240.

Choli, T., Henning, P., WittmannLiebold, B., and Reinhardt, R. (1988). Isolation, characterization and microsequence analysis of a small basic methylated DNA-binding protein from the Archaebacterium, Sulfolobus solfataricus. Biochim. Biophys. Acta 950, 193-203.

Clore, A. J., and Stedman, K. M. (2006). The SSV1 viral integrase is not essential. Virology 361, 103-111.

Fröls, S., Gordon, P. M., Panlilio, M. A., Schleper, C., and Sensen, C. W. (2007). Elucidating the transcription cycle of the UV-inducible hyperthermophilic archaeal virus SSV1 by DNA microarrays. Virology 365, 48-59.

Guo, L., Brügger, K., Liu, C., Shah, S. A., Zheng, H., Zhu, Y., Wang, S., Lillestøl, R. K., Chen, L., Frank, J., Prangishvili, D., Paulin, L., She, Q., Huang, L., and Garrett, R. A. (2011). Genome analyses of Icelandic strains of Sulfolobus islandicus model organisms for genetic and virus-host interaction studies. J. Bacteriol. 193, 1672-1680.

Guo, L., Feng, Y., Zhang, Z., Yao, H., Luo, Y., Wang, J., and Huang, L. (2008). Biochemical and structural characterization of Cren7, a novel chromatin protein conserved among crenarchaea. Nucleic Acids Res. 36, 1129-1137.

Held, N. L., and Whitaker, R. J. (2009). Viral biogeography revealed by signatures in Sulfolobus islandicus genomes. Environ. Microbiol. 11, 457-466.

Jonuscheit, M., Martusewitsch, E., Stedman, K. M., and Schleper, C. (2003). A reporter gene system for the hyperthermophilic archaeon Sulfolobus solfataricus based on a selectable and integrative shuttle vector. Mol. Microbiol. 48, 1241-1252.

Kessler, A., Sezonov, G., Guijarro, J. I., Desnoues, N., Rose, T., Delepierre, M., Bell, S. D., and Prangishvili, D. (2006). A novel archaeal regulatory protein, Stal, activates transcription from viral promoters. Nucleic Acids Res. 34, 4837-4845.

Lawrence, C. M., Menon, S., Eilers, B. J., Bothner, B., Khayat, R., Douglas, T., and Young, M. J. (2009). Structural and functional studies of archaeal viruses. J. Biol. Chem. 284, 12599-12603.

Martin, A., Yeats, S., Janekovic, D., Reiter, W. D., Aicher, W., and Zillig, W. (1984). SAV 1, a temperate u.v.inducible DNA virus-like particle from the archaebacterium Sulfolobus acidocaldarius isolate B12. EMBO J. 3, 2165-2168.

Menon, S. K., Eilers, B. J., Young, M. J., and Lawrence, C. M. (2010). The crystal structure of D212 from Sulfolobus spindle-shaped virus ragged hills reveals a new member of the PD-(D/E)XK nuclease superfamily. J. Virol. 84, 5890-5897.

Menon, S. K., Maaty, W. S., Corn, G. J., Kwok, S. C., Eilers, B. J., Kraft, P., Gillitzer, E., Young, M. J., Bothner, B., and Lawrence, C. M. (2008). Cysteine usage in Sulfolobus spindle-shaped virus 1 and extension to hyperthermophilic viruses in general. Virology 376, 270-278.

Nadal, M., Mirambeau, G., Forterre, P., Reiter, W. D., and Duguet, M. (1986). Positively supercoiled DNA in a virus-like particle of an archaebacterium. Nature 321, 256-258.

Palm, P., Schleper, C., Grampp, B., Yeats, S., McWilliam, P., Reiter, W.

\section{ACKNOWLEDGMENTS}

This research was supported by Portland State University, NASA award NNX07AT63A. Subaward G258-08-W1951 and NSF grant MCB-0702020. The authors would like to thank Adam Clore for his advice on Long Inverse PCR and SSV comparative genomics.

D., and Zillig, W. (1991). Complete nucleotide sequence of the virus SSV1 of the archaebacterium Sulfolobus shibatae. Virology 185 , 242-250.

Pina, M., Bize, A., Forterre, P., and Prangishvili, D. (2011). The archeoviruses. FEMS Microbiol. Rev. 35, 1035-1054.

Redder, P., Peng, X., Brügger, K., Shah, S. A., Roesch, F., Greve, B., She, Q., Schleper, C., Forterre, P., Garrett, R. A., and Prangishvili, D. (2009). Four newly isolated fuselloviruses from extreme geothermal environments reveal unusual morphologies and a possible interviral recombination mechanism. Environ. Microbiol. 11, 2849-2862.

Reiter, W. D., Palm, P., Henschen, A., Lottspeich, F., and Zillig, W. D. (1987a). Identification and characterization of the genes encoding three structural proteins of the Sulfolobus virus-like particle SSV1. Mol. Gen. Genet. 206, 144-153.

Reiter, W. D., Palm, P., Yeats, S., and Zillig, W. (1987b). Gene-expression in Archaebacteria - Physical mapping of constitutive and UV-inducible transcripts from the Sulfolobus virus-like particle SSV1. Mol. Gen. Genet. 209, 270-275.

Reno, M. L., Held, N. L., Fields, C. J., Burke, P. V., and Whitaker, R. J. (2009). Biogeography of the Sulfolobus pan-genome. Proc. Natl. Acad. Sci. U.S.A. 106, 8605-8610.

Schleper, C., Kubo, K., and Zillig, W. (1992). The particle SSV1 from the extremely thermophilic archaeon Sulfolobus is a virus: Demonstration of infectivity and of transfection with viral DNA. Proc. Natl. Acad. Sci. U.S.A. 89, 7645-7649.

She, Q., Singh, R. K., Confalonieri, F., Zivanovic, Y., Allard, G., Awayez, M. J., Chan-Weiher, C. C., Clausen, I. G., Curtis, B. A., De Moors, A., Erauso, G., Fletcher, C., Gordon, P. M., Heikamp-de Jong, I., Jeffries, A. C., Kozera, C. J., Medina, N., Peng, X., Thi-Ngoc, H. P., Redder, P., Schenk, M. E., Theriault, C., Tolstrup, N., Charlebois, R. L., Doolittle, W. F., Duguet, M., Gaasterland, T., Garrett, R. A., Ragan, M. A., Sensen, C. W., and Van der Oost, J. (2001). The complete genome of the crenarchaeon Sulfolobus solfataricus P2. Proc. Natl. Acad. Sci. U.S.A. 98, 7835-7840.

Stedman, K. M., Schleper, C., Rumpf, E., and Zillig, W. (1999). Genetic requirements for the function of the archaeal virus SSV1 in Sulfolobus solfataricus: construction and testing of viral shuttle vectors. Genetics 152 , 1397-1405.

Stedman, K. M., She, Q., Phan, H., Arnold, H. P., Holz, I., Garrett, R. A., and Zillig, W. (2003). Relationships between fuselloviruses infecting the extremely thermophilic archaeon Sulfolobus: SSV1 and SSV2. Res. Microbiol. 154, 295-302.

Wiedenheft, B., Stedman, K. M., Roberto, F., Willits, D., Gleske, A. K., Zoeller, L., Snyder, J., Douglas, T., and Young, M. (2004). Comparative genomic analysis of hyperthermophilic archaeal Fuselloviridae genomes. J. Virol. 78, 7438-7442.

Yeats, S., McWilliam, P., and Zillig, W. (1982). A plasmid in the archaebacterium Sulfolobus acidocaldarius. EMBO J. 1, 1035-1038.

Conflict of Interest Statement: The authors declare that the research was conducted in the absence of any commercial or financial relationships that could be construed as a potential conflict of interest.

Received: 15 March 2012; paper pending published: 16 April 2012; accepted: 15 May 2012; published online: 05 June 2012.

Citation: Iverson $E$ and Stedman $K$ (2012) A genetic study of SSV1, the prototypical fusellovirus. Front. Microbio. 3:200. doi: 10.3389/fmicb.2012.00200

This article was submitted to Frontiers in Evolutionary and Genomic Microbiology, a specialty of Frontiers in Microbiology. Copyright (c) 2012 Iverson and Stedman. This is an open-access article distributed under the terms of the Creative Commons Attribution Non Commercial License, which permits non-commercial use, distribution, and reproduction in other forums, provided the original authors and source are credited. 